\title{
Biology Instruction in the Nation's Elementary and Secondary Schools
}

\author{
Anton E. Lawson \\ Department of Zoology, Arizona State University, Tempe, AZ 85287-1501
}

More than 20 years ago, considerable work was begun to improve biology teaching in the United States. Until that time most teaching centered around fact-laden textbooks and consisted primarily of assign, recite, test, and then discuss the test. Apparently, for many biology teachers little has changed. In a review of teaching methods and materials, Hurd et al. (1980) reported the following facts: 1) Eighty percent of primary, $90 \%$ of intermediate, and $50 \%$ of all teachers base their instruction on a single textbook. 2) Almost all questions arise from information in the textbook and most center on terminology and definitions; teachers rely on and believe in the textbook. 3) Students are trained to seek the "right" answers from the textbook. 4) Throughout the history of biology teaching, and particularly in the last two decades, laboratory instruction has been stressed. The average textbook has laboratory activities amounting to $\approx 40 \%$ of the curriculum. Still, less than half of all biology teachers regularly use laboratory activities, and $25 \%$ report that they either never use such activities or do so no more than once a month. 5) The common sequence of instruction is assign, recite, test, and discuss the test, all based on the textbook.

A more recent review by the National Research Council (NRC) (1990) paints virtually the same picture. Given that teachers rely so heavily on textbooks and that textbooks are generally of poor quality and vastly overburdened with terminology, Yeager (1983) reports that the most popular high school biology textbook contains an average of 23 special biological terms per page. It is little wonder that many students leave our high schools scientifically illiterate and totally uninspired toward scientific endeavors. In the words of the NRC: "...science is viewed as arcane, difficult, practiced only by the very talented, and unrelated to the real world of the average person. For most students, instead of dispelling those notions, the 10th-grade biology course simply reinforces them. The course also does little to develop scientific reasoning, teach cause and effect, encourage skepticism, or suggest the value of experimental observation."

One should not infer from this bleak picture that high-quality science curricula do not exist. Indeed they do exist, particularly at the elementary level. One such program, developed with National Science Foundation funding during the 1960s and 1970s at the Univ. of California, Berkeley, is called the Science Curriculum Improvement Study. When implemented, this curriculum has proven to be extremely effective at helping students acquire meaningful conceptual understanding, scientific reasoning skills, and positive attitudes toward science (for a review see Lawson et al., 1989). The basic problem at the elementary level is not that good programs do not exist, rather it is that our-educational system of district level control makes it extremely difficult to implement these programs on a wide scale. A review of effective but poorly implemented programs at other levels is contained in the NRC report (1990).

District level control impedes the dissemination and implementation of quality curricula. Poor university level instruction constitutes an equally serious impediment to training effective science teachers. It is well known that teachers "teach as they have been taught." Because science teachers have been taught mostly by university professors, typically via the lecture method, and because virtually all university-level science laboratories are of the "cookbook" variety (i.e., students are not only told what they will find but also how to find it), it is little wonder that public school teachers do not know how to teach science effectively. Consequently, my primary purpose is to encourage you to teach university-level science courses in ways that will solve this problem, not contribute to it.

\section{Principles of effective science instruction}

The American Association for the Advancement of Science (AAAS, 1989) has recently begun a long-term project, named Project 2061 in honor of the year Halley's comet returns to earth, to improve science instruction in the nation's schools. The initial phase of Project 2061 has not only identified the scientific concepts and reasoning skills that elementary and secondary students should acquire, but also listed teaching principles that should be used to teach those concepts and skills. Based on current educational and psychological research, they list five basic principles and several subprinciples:

1) Teaching should be consistent with the nature of scientific inquiry.

- Start with questions about nature.

- Engage students actively.

- Concentrate on the collection and use of evidence.

- Provide historical perspectives.

- Insist on clear expression.

- Use a team approach.

- Do not separate knowing from finding out.

- Deemphasize the memorization of technical vocabulary.

2) Science teaching should reflect scientific values.

- Welcome curiosity.

- Reward creativity.

- Encourage a spirit of healthy questioning.

- Avoid dogmatism.

- Promote aesthetic responses.

3) Teaching should aim to counteract learning anxieties.

- Build on success.

- Provide abundant experience in using tools.

- Support the roles of girls and minorities in science.

- Emphasize group learning.

4) Science teaching should extend beyond the school.

5) Teaching should take its time.

\section{Implementing the principles: A simple example}

Below is a simple example of how some of these principles can be implemented. I will start by teaching a concept in the traditional teacher-directed manner to provide a basis for comparison. I intend to teach you the Skint concept. A Skint is defined as a two-dimensional "creature" that possesses straight sides and parallel lines that cover its surface (Elementary Science Study, 1974). Note the "creatures" in Fig. 1 below. These are all Skints because each creature has straight sides and parallel lines on its surface.

\section{All of these are Skink}

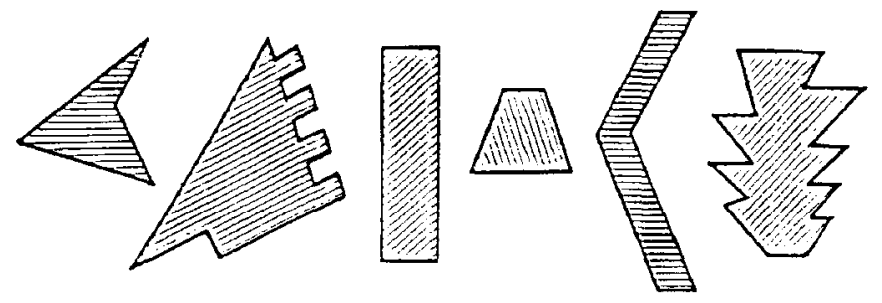


None of these is a Skint.

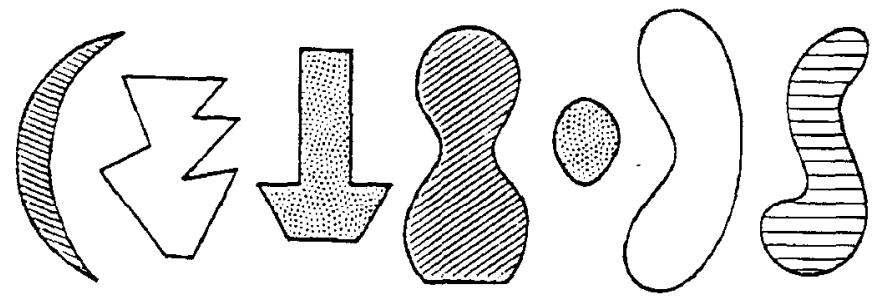

Now look at the creatures in Fig. 2 above and note that none of these have both features; hence, none of these are Skints.

To see if you have acquired the Skint concept, turn your attention to Fig. 3 below and see if you can identify the Skints. If you identified creatures 1, 2, and 4 as Skints, you are correct and have acquired the concept.

Which of these are Skints?
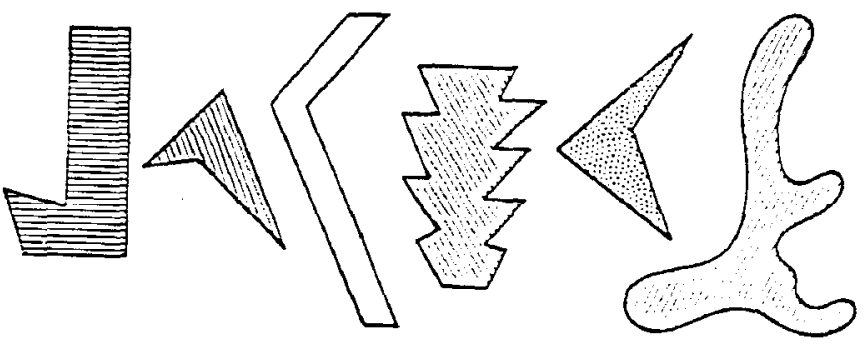

The teaching procedure just used consists of three basic steps: 1) introduce a new term and define the term, 2) provide examples and nonexamples, and 3) test. The results of this procedure (assuming students pay attention) are: 1) students acquire new concepts (i.e., patterns of regularity plus new terms), and 2) students learn to rely on the teacher for new knowledge.

Now consider an alternative teaching approach based on the AAAS principles. Start by observing the creatures in Fig. 4 below (Elementary Science Study, 1974). These are all Mellinarks because they all have some thing(s) in common.

All of these are Mellinarks.

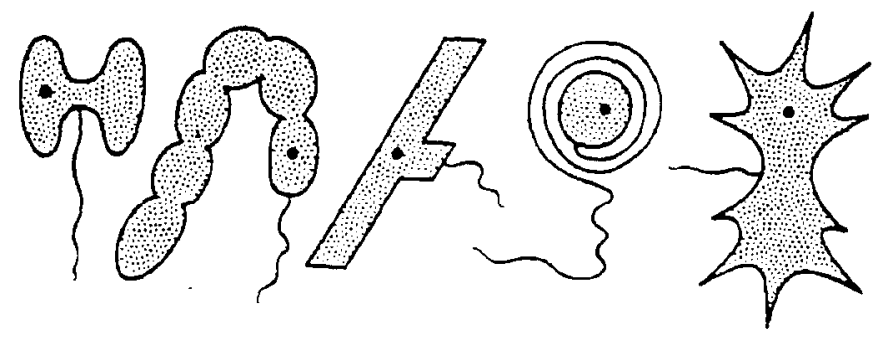

Compare the Mellinarks in Fig. 4 with the non-Mellinarks in Fig. 5 below. Can you identify the distinguishing features of Mellinarks?

None of these is a Mellinark.
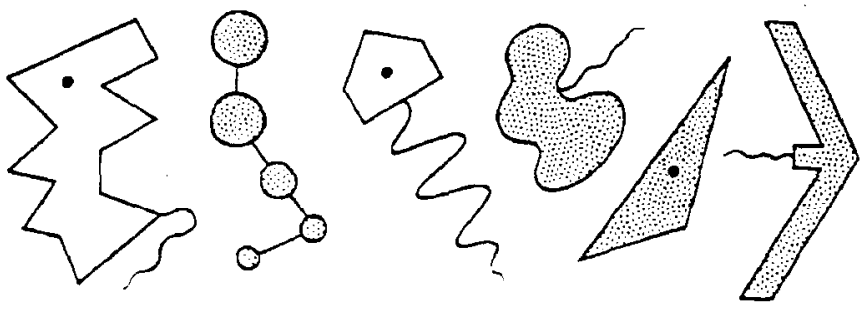

Now turn to Fig. 6. Which of the creatures in Fig. 6 are Mellinarks? The answer appears at the end of this article.
Which of these are Mellinarks?
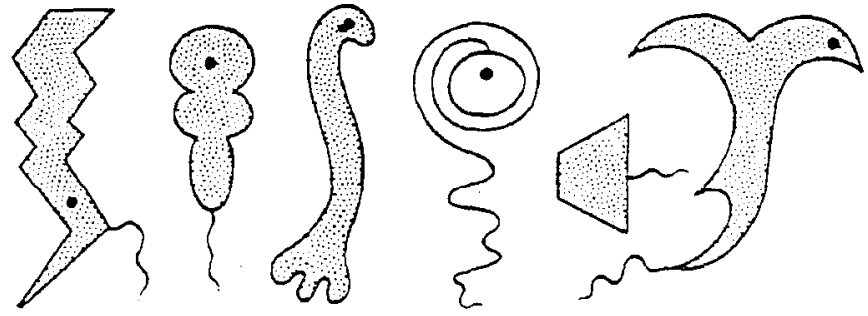

Quite obviously, this alternative teaching procedure involves much less direction from the teacher and is more demanding on the student's thought process. It also is a lot more enjoyable for both teacher and student. The procedure consists of three basic steps: 1) provide students with an opportunity to explore new data and to discover a "pattern" of regularity, 2) introduce a term to be linked to the pattern, and 3) provide students with an opportunity to test their new knowledge by trying to apply it in a new context. In this case the new data were presented in Figs. 4 and 5, the discovered pattern was "tail" + "eye spot" + "little dots," and the term was Mellinark. The new context in which students had an opportunity to apply the new concept was the creatures shown in Fig. 6. This alternative teaching approach, which consists of three basic phases-exploration, term introduction, and concept application-is called the learning cycle (Lawson et al., 1989).

The results of using the learning cycle approach are that the students 1) acquire new concepts, 2) learn to rely on themselves and their peers for knowledge, and 3) learn how to acquire knowledge, i.e., they learn how to learn. Because internally generated learning requires one to think, we can also conclude that the learning cycle approach helps students learn how to think. Research reviewed in Lawson et al. (1989) provides considerable support for these conclusions.

Of course the "hypothetic0-deductive" thinking required to solve the Mellinark, and similar tasks, is not at all difficult for trained scientists, but it does often prove to be difficult for high school students. The thinking consists primarily of generating ideas (e.g., Mellinarks are spotted creatures), deducing their consequences (none of the creatures in row two should be spotted), checking the evidence (some of the creatures in row two are spotted), drawing conclusions (my idea must be wrong), trying again with a new idea (Mellinarks have tails), and so on until you find an idea that is consistent with the evidence. Notice how a successful student uses this pattern in the following transcripted interview:

(Student) Numbers one, two, and six are Mellinarks.

(Teacher) OK, how did you figure that out?

(Student) Urn. Well, the first thing I started looking for was just overall shape, whether it's straight, looks like a dumbbell, but this doesn't really work, because some of these (row two) are similar in overall body shape. So I ruled that out. Well, then I said, all of these are spotted (row one). But some of these (row two) are spotted and these aren't Mellinarks, so that can't be the only thing. So I looked back at these (row one) and noticed that they all have a tail. But some of these have a tail (row two), so that can't be the only thing either. So then I was sort of confused and had to look back and think about what else it was. Then I saw the big dot. So all of these (row one) have all three things, but none of these (row two) have all three.

Notice the hypothetico-deductive reasoning pattern employed. First, the idea that shape is a critical feature is generated, tested, and rejected. Then the idea that the presence of spots is a critical feature is generated, tested, and rejected. Finally, the student began to consider combinations of features and quickly arrived at an idea consistent with all of the data. Contrast this successful student's remarks with the remarks of the following nonsuccessful student:

(Teacher) Suppose I define a Mellinark as being a creature with a tail. How could I test to see if that idea is right or not.

(Student) Urn... you could um... huh....... just look to see if the other creatures have the same tails...or, I mean...you 
know...characteristics of the creatures...with the tails and the points and the dots and stuff to see they are...you know...all the same or close to.. and then...um...heh...I don't know...heh. (Teacher) OK, let's look at the second row. We know that none of these are Mellinarks. So what would you expect about these with regard to tails? I mean, if it's true that Mellinarks are creatures with tails, then what would you expect to find in row two with regard to tails?

(Student) Urn...they would a...they would be some different kind of creature with tails...I don't know...they would um...I don'tknow...they would just...they don't have the dots on 'em. And then...um...they are more.. .I don't know.

(Teacher) OK. Let's go back. Once again, I'm going to say that Mellinarks are creatures with tails and I look down here (row two) and see that this non-Mellinark has a tail. See that tail right there?

(Student) Yeah.

(Teacher) And I know that that is not a Mellinark. So I would conclude from that that my definition must be wrong.

(Student) Yeah...well they could have classified 'em wrong. It could have been a mistake. These would have been up with the other Mellinarks.

(Teacher) Yes, that's a possibility. But let's assume that's not the case. Let's assume that they did it right. That is, let's take it as the truth that none of these in row two are Mellinarks. So, the other alternative is that I got my ideas wrong. Mellinarks aren't creatures with tails after all, or maybe they do have tails but there is something else in addition to tails that Mellinarks have. (Student) OK.

(Teacher) So let's look and see what else there might be. I see that these all have little dots. So maybe a Mellinark is a creature with a tail and little dots. Does that seem like a good definition to you?

(Student) I think then that number one, two, five, and six on the bottom would all be Mellinarks.

(Teacher) OK, they all fit the definition. But let's look at the second row and see if that tells us anything about whether I've got a good definition.

(Student) Urn...number four could be a Mellinark depending upon it's own classification. And number six because they both have tails and they have the dots...and um...number one and three...like...they just don't seem to fit in like number four at the bottom...but they still have the same tail...I don't know.

(Teacher) OK. But notice once again that we are told that numbers four and six are not Mellinarks. What does that tell me about my definition?

(Student) Urn...that they probably interacted with some of the other creatures and they produced Mellinarks that you guys didn't think were Mellinarks.

(Teacher) Might it tell me that my definition is wrong? (Student) It wouldn't tell that I was wrong...that is...I would just say that...um...oh yeah...they don't have the black solid dots...they are just different I guess.

The startling aspect of this response is the student's unwillingness/ inability to consider that his initial idea might be wrong, even after 'repeated attempts by the interviewer to get him to do so. ("Might it tell me that my definition is wrong?" "No...It wouldn't tell that I was wrong...”) Instead of recognizing, for example, that figures four and six in row two contradict the idea that Mellinarks are creatures with tails and little dots, the student concludes that they are indeed Mellinarks but that they were put in the wrong row! (i.e., "They probably interacted with some other creatures and they produced Mellinarks that you guys didn't think were Mellinarks.") Thus, instead of using the data to test an idea, the student modified the data to fit his ideas.

I am sure you would all agree that the above student has a problem. Unfortunately, he is not the only one of his kind. Most estimates put the percentage of high school and even lower-level college students with similar thinking problems at $\approx 30 \%$ to $50 \%$ of the population. Fortunately, students like this can be helped with effective instruction. The next section will provide an example of how.
Using the AAAS teaching principles and the learning cycle to teach mitosis

The example lesson intends to teach the concept of mitosis. The lesson will be presented in two parts. The first part, the teacher material, provides specific teaching tips for each phase of the learning cycle. The second part is the student material as it would appear in the laboratory manual.

In my view, a major goal in any learning cycle, including one on mitosis, is to engage students in a real (to them) scientific investigation. It should be clear that scientists are motivated to engage in investigations to answer questions about nature, such as: "How do multicellular organisms grow?" Consequently, notice how the learning cycle begins with this question. Notice also how it engages students in generating and testing alternative hypotheses in a hypothetico-deductive fashion. Admittedly, one example is insufficient to enable you to modify your entire course to incorporate these teaching principles and methods. Indeed, you may have already incorporated many of these principles into your course. Or, perish the thought, you may be unconvinced that you should incorporate these principles. A common argument against doing so is that there are simply too many facts and terms to teach to waste valuable time on student inquiry. However, I find this to be a very hollow argument and at a moment's reflection you probably will also. Most of us know from our experience as students that when we were required merely to memorize facts and terms at a rapid-fire rate, most of what we had memorized was soon lost. Also, it should be clear that rapid-fire content coverage does nothing to help students learn how to think. And last, such superficial treatment sends precisely the wrong message to future secondary and/or elementary teachers about the nature of science and how it should be taught.

\section{TEACHER MATERIAL}

\section{How do multicellular organisms grow?}

\section{Teaching tips}

1) Initiate the investigation with reference to the introductory paragraph in the student material. Write the question, How do multicellular organisms grow?, on the board and encourage students to speculate about some possible mechanisms (e.g., What might be occurring at the cellular level to account for the increase in organism size?). This part of the laboratory exercise should resemble a brainstorming session where any and all ideas are viewed as acceptable and are written on the board and labeled as "alternative hypotheses."

\section{Exploration}

2) Students should already know the names of obvious cell structures (e.g., cell membrane, cell wall, cytoplasm, nucleus) from previous laboratory exercises. If not, introduce these terms after initial observations have been made.

3) Tell the students they are observing slides of a growing root tip (etc.), but do not mention the process of cell elongation or cell division at this time. Their job during exploration is to think about what their hypotheses lead them to expect to find and then observe carefully to see if those expectations are confirmed. For example, if they have hypothesized that growth takes place due to the increase in the amount of space between adjacent cells, then they should expect (predict) to see more space between the cells in older portions of the stems, roots (i.e., those areas farther away from the tips). Likewise, if they hypothesized that growth takes place due to an increase in cell size, then the prediction follows that cells further away from the tips should be larger than those near the tips. On the other hand, if they think that growth occurs solely due to the increase in the number of cells, then no obvious differences in cell size are predicted.

4) If students have trouble locating relevant differences, or in deciding what to look for to test their ideas, stop the class. Use a quick drawing on the board to help them locate the best area of the slide for viewing. You may also need to discuss specific hypotheses and predictions as stated above. You may want to cue students to look for changes in the thread-like structures near the cell's center and intro- 
duce the term chromosome at this time to refer to those structures. You may also want to challenge students to see if they can determine whether the observed differences among the cells are due to differences in cell types or within one type of cell that is undergoing some sort of change.

5) After students have observed the drawings of other students, hold a class discussion to answer the following questions: What hypotheses have been supported/contradicted? What are the major differences among the observed cells? Also discuss student responses to these questions. If a student hypothesizes that we are observing a sequence of changes in a single cell type, ask how this idea might be tested. If no student advances this hypothesis, advance it yourself.

6) Before showing the film loop on cell division ("Mitosis: A Single Topic Inquiry Film," Biological Sciences Curriculum Study, 1967), compare the various sequences that students have generated to discover similarities and differences.

7) Show the film loop to discover which of the hypothesized sequences seems most correct.

\section{Term introduction}

8) Introduce the term "cell elongation" after the students have discovered the elongated cells that appear on the root tip and stem slides.

9) After deciding which sequence of cell changes seems most correct, introduce the term "mitosis" to refer to the replication of chromosomes during the cell division process.

10) Avoid showing students visual materials that emphasize stage names and discrete steps. Emphasize cell division and mitosis as dynamic processes.

\section{Concept application}

11) Have students view and discuss the process of meiosis as an extension of the cell division process in which the number of chromosomes is reduced to one-half of its original number in the resulting egg and sperm cells.

\section{STUDENT MATERIAL}

\section{How do multicellular organisms grow?}

Two characteristics of living things are 1) they are composed of one or more cells and 2) they grow. But how do multicellular organisms grow? What exactly happens at the tissue and cellular levels to enable the organism to increase in size? Generate as many alternative hypotheses as you can. In this lab, you will use the microscope to observe tissues and cells of rapidly growing portions of plants and animals to discover which, if any or all, of your hypotheses are correct.

\section{Objectives}

1) To observe and record differences among the tissues and cells in growing organisms.

2) To test alternative hypotheses that attempt to explain growth in multicellular organisms in terms of changes at the cellular level.

\section{Materials}

Prepared slides of growing portions of plants; microscopes; lens paper; string; yarn; red and white pipe cleaners; large sheets of paper; markers.

\section{Procedure}

1) Make microscopic observations of the tissues and cells of the specimen(s) to try to answer the following questions: What differences in cell size, structure, and spacing exist? What areas appear to be the youngest or oldest? Do your observations support or refute any of your alternative hypotheses? If so, why?

2) While observing, make clear drawings of any differences you see among the cells. While observing the root tip slide, pay particular attention to possible differences in cell size in different locations of the root tip. Also, note possible differences in thread-like structures in the cell nuclei. These are called chromosomes. Make as many drawings as you like. Label all obvious cell structures.

3) Make an enlargement of your drawings on a large sheet of paper. These should be large and clear enough so that all students can see them when hung up around the room.

4) Carefully observe all of the drawings.

5) On the root tip slides, do you think we are looking at many types of cells or at one type of cell that is going through changes? Explain.

6) If you think the cells are going through changes, number your drawings in an order that might reflect the order of those changes. Sketch that sequence.

7) Which, if any, of the initial alternative hypotheses are supported by the class's observations? Explain.

8) What additional observations would be helpful to test your ideas?

9) Compare your hypothesized sequence of changes with the apparent sequence shown in the film loop. Does this suggest that you need to modify your sequences? If so, what modifications are needed?

Unfortunately, biology instruction in the nation's elementary and secondary schools is a matter of dull textbook- and lecture-driven memorization of largely meaningless terms. What is even more regrettable is that high-quality and very effective investigative programs have been developed during the past 20 years, but these programs remain severely underused. The reasons for this are no doubt varied, but a strong case can be made that a serious impediment to change is the way biology is taught to future teachers in our universities. As long as biology professors continue to send the message, by the ways they teach and evaluate learning, to these future teachers that biology is the mere collection of "facts" and the memorization of huge numbers of terms, very little can be done to change what is now a very sorry state of affairs.

Answer to the Mellinark puzzle. Creatures 1, 2, and 6 of Fig. 6 are Mellinarks.

\section{Literature Cited}

American Association for the Advancement of Science. 1989. Science for all Americans. Amer. Assn. Advancement Sci., Washington, D.C.

Elementary Science Study. 1974. Attribute games and problems: Teacher's guide. McGraw-Hill, New York.

Hurd, P.D., R.W. Bybee, J.B. Kahle, and R.E. Yeager. 1980. Biology education in secondary schools of the United States. Amer. Biol. Teacher 43(7):388410.

Lawson, A.E., M.R. Abraham, and J.W. Renner. 1989. A theory of instruction: Using the learning cycle to teach science concepts and thinking skills. Natl. Assoc. Res. Sci. Teaching, Cincinnati.

National Research Council. 1990. Fulfilling the promise: Biology education in the nation's schools. National Academy Press, Washington, D.C.

Yeager, R.E. The importance of terminology in teaching K-12 science. J. Res. Sci. Teaching 20(6):577-588. 